\title{
Full recovery of contraction late after acute myocardial infarction: determinants and early predictors
}

\author{
P Lancellotti, A Albert, C Berthe, L A Piérard
}

\begin{abstract}
Objectives-To assess the relative value of electrocardiographic, echocardiographic, angiographic, and in-hospital therapeutic indices for predicting late functional recovery after acute myocardial infarction, and to determine the variables associated with absence of recovery, partial recovery, and full recovery.

Design-Prospective observational follow up study.

Setting-Teaching hospital.

Patients-74 consecutive patients with a first uncomplicated acute myocardial infarct.

Interventions-Dobutamine-atropine stress echocardiography was performed mean (SD) 5 (2) days after the acute event. Quantitative angiography was available in all patients before hospital discharge. A follow up resting echocardiogram was obtained 12 (2) months later.

Results-Functional recovery (partial, $\mathrm{n}=18$; full, $\mathrm{n}=27$ ) was observed in 45 of the 74 patients. Recovery was associated with earlier thrombolytic treatment $(p=0.008)$, earlier peak concentration of creatine kinase $(p=0.009)$, greater contractile reserve $(p=0.0001)$, non- $Q$ wave acute myocardial infarction $(\mathrm{p}=0.002)$, and more frequent elective angioplasty of the infarct related vessel $(p=0.0004)$. Three independent variables were selected stepwise from multivariate analysis for predicting late recovery: contractile reserve $\left(\chi^{2}=24.2, \mathrm{p}<0.0001\right)$; non-Q wave infarction $\left(\chi^{2}=15.7, \mathrm{p}=0.0001\right)$; and the time from symptom onset to thrombolysis $\left(\chi^{2}=4.94, \mathrm{p}=0.026\right)$. Three independent variables predicted full recovery: contractile reserve $\left(\chi^{2}=17.2, \mathrm{p}=0.0001\right)$; non- $\mathrm{Q}$ wave infarction $\left(\chi^{2}=10.1, \mathrm{p}=0.0016\right)$; and elective angioplasty of the infarct related artery $\left(\chi^{2}=4.53, \mathrm{p}=0.033\right)$. Only contractile reserve $\left(\chi^{2}=17.0\right.$, $\mathrm{p}<0.001$ ) was selected from the multivariate analysis for its ability to distinguish between partial recovery and absence of recovery.

Conclusions-Late recovery of contraction relates to earlier treatment, which is associated with lower infarct size unmasked by a non-Q wave event and the presence of contractile reserve. Elective coronary angioplasty of the infarct related artery before hospital discharge is associated with full recovery.

(Heart 2001;85:521-526)
\end{abstract}

Keywords: myocardial infarction; echocardiography; prognosis; angioplasty

Several mechanisms can arrest the progression of the wavefront migration of myocardial necrosis after coronary artery occlusion ${ }^{1}$ : availability of a recruitable collateral circulation; spontaneous reperfusion; and, more often, early coronary intervention through the use of thrombolytic treatment or primary coronary angioplasty. The extent of myocardial salvage relies on rapid, complete, and sustained coronary recanalisation with adequate myocardial tissue perfusion. ${ }^{2}$ Because the endocardial half of the myocardium makes the main contribution to systolic thickening at rest, ${ }^{3}$ regional function will only improve or normalise if most of the thickness of the ventricular myocardium has escaped necrosis. ${ }^{4}$

Functional recovery can be delayed because of postischaemic dysfunction or recurrent episodes of myocardial ischaemia or stunning. A flow limiting residual stenosis of the infarct related artery is common after acute myocardial infarction. ${ }^{5}$ Low residual perfusion or blunted flow reserve may result in hibernating myocardium, with ultrastructural abnormalities including loss of contractile material. ${ }^{6}$ Timely revascularisation is required in this condition. Too early follow up may result in underestimation of the extent of possible functional improvement, which can continue to progress.

The time course of functional improvement remains controversial. Although some studies suggest that most improvement occurs within the first days or weeks, ${ }^{7}$ other investigations indicate that functional recovery may be delayed for up to several months. ${ }^{89}$ The incidence, predictors, and determinants of late full recovery have never been studied specifically. This study was undertaken to assess the relative value of electrocardiographic, echocardiographic, angiographic, and in-hospital therapeutic indices for predicting late functional recovery after acute myocardial infarction, and to determine the variables associated with full, partial, or absent recovery.

\section{Methods}

STUDY PATIENTS

We enrolled prospectively 96 consecutive patients admitted for a first uncomplicated acute myocardial infarct. The diagnosis of acute myocardial infarction was made on the basis of typical ischaemic chest pain, acute ST segment elevation in two or more leads, and 
characteristic evolution of serum creatine kinase. We excluded patients with valvar heart disease $(n=1)$, previous myocardial infarction $(n=5)$, and contraindications to dobutamine infusion, including postinfarction angina $(n=1)$, left ventricular failure $(n=1)$, and major ventricular arrhythmias $(n=1)$. Two patients died during the follow up and 11 failed to return for follow up echocardiography. The study population consisted of the 74 remaining patients (56 men and 18 women). Their mean (SD) age was 57 (10) years (range 37-85 years). The infarct location on the admission ECG was anterior in 33 patients, lateral in 10, and inferior in 31.

All patients underwent dobutamine stress echocardiography within 5 (2) days after the acute ischaemic event and before coronary angiography. A follow up echocardiogram was obtained 12 (2) months after the infarct.

All patients gave informed consent, and the study protocol was approved by the institutional medical ethics committee.

DOBUTAMINE STRESS ECHOCARDIOGRAPHY

$\beta$ Adrenergic blocking agents were withdrawn 48 hours before the study. Dobutamine was infused intravenously under continuous ECG monitoring by a volumetric pump at initial doses of 5 and $10 \mu \mathrm{g} / \mathrm{kg} / \mathrm{min}$ for three minutes each, followed by increments of $10 \mu \mathrm{g} / \mathrm{kg} / \mathrm{min}$ every three minutes up to a maximum dose of $40 \mu \mathrm{g} / \mathrm{kg} / \mathrm{min}$. Atropine $(0.25 \mathrm{mg}$ to a maximum of $1 \mathrm{mg}$ ) was added if the target heart rate $(85 \%$ of maximum age predicted heart rate) was not obtained with dobutamine only. End points for dobutamine infusion were: maximum dose, target heart rate, limiting chest pain, $\geqslant 2 \mathrm{~mm}$ ST segment depression compared with baseline in two or more leads, new or worsening wall motion abnormalities, significant arrhythmias, severe hypertension (blood pressure $>230 / 120 \mathrm{~mm} \mathrm{Hg}$ ), or hypotension (decrease in systolic blood pressure $>30 \mathrm{~mm} \mathrm{Hg}$ ). Cross sectional echocardiography was done throughout the test; it was recorded on videotape and digitised on-line on optical disks at rest and during the last minute of each stage. Blood pressure was measured at each stage by arm cuff sphygmomanometry.

ECHOCARDIOGRAPHIC ANALYSIS

All echocardiograms were reviewed by two observers unaware of the clinical data. Semiquantitative analysis of wall thickening was performed using the classical 16 segment model. Wall thickening assessment of each segment was performed using a four point scoring system: 1 = normal wall thickening; 2 = hypokinesia; 3 = akinesia; $4=$ dyskinesia. Regional dyssynergy was defined when a score $\geqslant 2$ was assigned to a myocardial segment in two different echocardiographic views. Contractile reserve was defined as an improvement in wall thickening of $\geqslant 1$ grade. A dyskinetic segment (score 4) becoming akinetic (score 3) during stress was not considered viable. The development of new or worsened regional dyssynergy in the infarcted area during dobutamine stress was considered to indicate ischaemia. Four different echocardiographic responses were identified: sustained improvement implied improvement of contractility in dyssynergic segments until peak dose without deterioration; biphasic response was defined as an initial improvement of contractility by $\geqslant 1$ score at low dose dobutamine followed by subsequent worsening at high dose; worsening in adjacent area corresponded to the development of new dyssynergy adjacent to the infarcted zone with no change in the affected segments; akinesis without change was defined as no change in basal asynergy throughout the test.

FOLLOW UP ECHOCARDIOGRAPHY

Follow up echocardiograms were compared with the corresponding rest image obtained in the acute stage for comparative segmental analysis. Full functional recovery was defined as a normalisation of wall motion and thickening in the affected area. Partial recovery was defined as persistence of dyssynergy but improvement in wall thickening in at least two contiguous dyssynergic segments (from score 4 or 3 to 2 or 1 , and from score 2 to 1 ).

\section{ANGIOGRAPHY}

Quantitative coronary angiography and left ventriculography were performed in all patients within one week of dobutamine stress echocardiography. All coronary stenoses were measured quantitatively using the CMS system. ${ }^{10}$ In the presence of $>50 \%$ residual diameter stenosis of the infarct related artery, elective percutaneous transluminal coronary angioplasty (PTCA) was performed by an experienced cardiologist unaware of the results of dobutamine stress echocardiography. These results were not used in making the decision to perform PTCA.

\section{STATISTICAL ANALYSIS}

Quantitative data are expressed as mean (SD), and percentages are used for categorical findings. Because outcome was defined as an ordinal variable (no recovery (group 1), partial recovery (group 2), and full recovery (group 3)), stepwise ordinal logistic regression (SAS PROC LOGISTIC, version 6.12) was used to assess the predictive power of each variable and to identify the subset of variables that jointly provided the best prediction of outcome. ${ }^{11}$ The statistical criterion used in ordinal logistic regression is asymptotically distributed as a $\chi^{2}$ test with $\mathrm{k}+2$ degrees of freedom where $\mathrm{k}$ is the number of variables in the model. To highlight factors specifically related to full and partial functional recovery, we performed additional statistical analysis using a stepwise logistic discriminant model. Results are considered significant at $\mathrm{p}<0.05$.

\section{Results}

CLINICAL AND ANGIOGRAPHIC CHARACTERISTICS No patient was treated by primary PTCA. Fifty five patients $(74 \%)$ received thrombolytic treatment. Mean (SD) time from symptom onset to thrombolysis was 151 (102) minutes (range 15-720 minutes). Peak creatine kinase 
Table 1 Relation between stress echocardiographic responses, angiographic indices, and functional recovery

\begin{tabular}{lccc}
\hline DSE responses & $\begin{array}{l}\text { No recovery } \\
(n=29)\end{array}$ & $\begin{array}{l}\text { Partial recovery } \\
(n=18)\end{array}$ & $\begin{array}{l}\text { Full recovery } \\
(n=27)\end{array}$ \\
\hline Sustained improvement & $0(0),[0 / 0]$ & $3(2),[2 / 2]$ & $7(4),[2 / 2]$ \\
Biphasic response & $4(3),[0 / 0]$ & $12(8),[0 / 0]$ & $13(13),[2 / 2]$ \\
Worsening in adjacent area & $6(2),[0 / 0]$ & $2(1),[1 / 1]$ & $2(0),[1 / 1]$ \\
Unchanged wall motion & $19(5),[5 / 3]$ & $1(1),[0 / 0]$ & $5(5),[3 / 3]$ \\
\hline
\end{tabular}

Values are $\mathrm{n}$ (n with PTCA), [occluded infarct related artery/PTCA].

DSE, dobutamine stress echocardiography.

(CK) was 1765 (1142) IU/l, and peak creatine kinase $\mathrm{MB}$ isoenzyme (CK-MB) was 185 (161) IU/1. Time to peak CK was 13.6 (5.6) hours. Left ventricular ejection fraction was 51 (15)\%. The culprit vessel was the left anterior descending coronary artery in 33 patients, the left circumflex coronary artery in 10, and the right coronary artery in 31 . Sixteen patients had persistent occlusion of the infarct related artery. Residual stenosis of the patent infarct related artery was $68(7) \%$. Forty four patients underwent successful elective PTCA.

DOBUTAMINE ECHOCARDIOGRAPHIC FINDINGS

No complications occurred as a result of dobutamine stress echocardiography. Of the 1184 segments, 250 (21\%) were dyssynergic at baseline: 73 were hypokinetic, 167 were akinetic, and 10 dyskinetic. Of these 250 dyssynergic segments, $111(44 \%)$ improved at low dose of dobutamine and $139(56 \%)$ showed new or worsening dyssynergy at high dose. Contractile reserve and residual ischaemia were identified in 39 patients. Sustained improvement was observed in 10 patients, a biphasic response in 29 , worsening in adjacent area in 10, and akinesis without change in the 25 remaining patients.

FUNCTIONAL RECOVERY

During follow up, no cardiac event was recorded. No patient underwent bypass surgery, repeated PTCA, or reinfarction. At follow up, 149 segments were dyssynergic, 112 akinetic, and 27 hypokinetic. No dyskinetic segment improved contractility at follow up. Twenty nine patients had no functional recovery (group 1). Functional recovery was demonstrated in 45 of the 74 patients. Recovery was partial in 18 patients (group 2) and full in 27 (group 3).

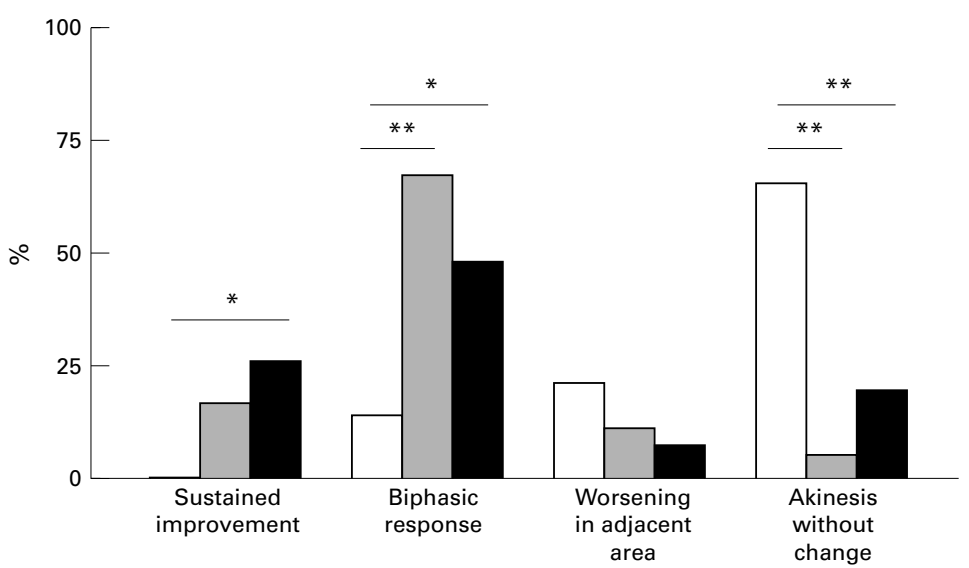

Figure 1 Bar graph showing types of response to dobutamine administration in the three subgroups. Left white bar, no recovery; middle grey bar, partial recovery; right black bar, full recovery. ${ }^{\star} p<0.01 ;{ }^{\star \star} p<0.001$.
RELATION BETWEEN STRESS ECHOCARDIOGRAPHIC RESPONSES, ANGIOGRAPHIC VARIABLES, AND RECOVERY

Table 1 shows the distribution of dobutamine wall motion responses in the three groups and their relation to angiographic variables. Akinesia without change was more often observed in patients who did not recover (19 of 29, $66 \% ; \mathrm{p}<0.001)$. In contrast, sustained improvement was not seen in any patient in this group. A biphasic response was more often observed in patients with functional recovery at follow up, particularly in group 2 (12 of 18 , $67 \%$ ) (fig 1). All 13 patients with a biphasic response and full late recovery underwent elective PTCA before discharge. Full recovery also occurred in five patients who had persistent akinesia during the early stress test. Three of these five patients had an occluded infarct related artery with collaterals, and two had severe $(>70 \%)$ residual stenosis and low minimum lumen diameter $(0.66 \mathrm{~mm}$ and $0.70 \mathrm{~mm}$, respectively). Elective PTCA was successful in all five patients.

\section{DISTINCTION BETWEEN PATIENTS WITH AND} WITHOUT FUNCTIONAL RECOVERY

A comparison between patients with and without late functional recovery is shown in table 2 . There were no significant associations between outcome and age, sex, site of infarction, thrombolytic treatment, echocardiographic score index at baseline, residual stenosis, and minimum lumen diameter of the infarct related artery. Time from symptom onset to thrombolytic treatment was shorter $(p=0.008)$ in patients with full recovery, and such patients were more likely to have non-Q wave infarction $(p=0.002)$. Peak concentration of CK was higher $(p=0.008)$ and occurred later $(\mathrm{p}=0.009)$ in patients without recovery. Contractile reserve was most often observed in patients with recovery, either partial or full $(p=0.0001)$. The incidence of residual ischaemia in the affected area was not different in the three subgroups. Elective PTCA of the infarct related artery was more often undertaken in patients with recovery, especially in those who recovered fully (22 of 27 patients) $(p=0.0004)$. Three independent variables distinguishing outcomes were selected from multivariate analysis: contractile reserve $\left(\chi^{2}=24.2, \mathrm{p}<0.0001\right)$; non-Q wave infarction $\left(\chi^{2}=15.7, \mathrm{p}=0.0001\right)$; and time to treatment $\leqslant 140$ minutes $\left(\chi^{2}=4.9, \mathrm{p}=0.026\right)$. The percentage of correct classification was about $78 \%$.

\section{PREDICTORS OF FULL FUNCTIONAL RECOVERY}

Three independent variables distinguishing patients with full recovery and those without recovery were selected from logistic discriminant analysis (table 3): contractile reserve detected on dobutamine stress echocardiography $\left(\chi^{2}=17.2, \mathrm{p}=0.0001\right)$; non-Q wave infarction $\left(\chi^{2}=10.1, \mathrm{p}=0.0016\right)$; and elective PTCA of the infarct related artery $\left(\chi^{2}=4.53, \mathrm{p}=0.033\right)$. Only contractile reserve $\left(\chi^{2}=17.0, \mathrm{p}<0.001\right)$ was selected from the multivariate analysis for distinction between 
Table 2 Comparison between patients with and without recovery (partial and full)

\begin{tabular}{lllll}
\hline Variables & $\begin{array}{l}\text { No recovery } \\
(n=29)\end{array}$ & $\begin{array}{l}\text { Partial recovery } \\
(n=18)\end{array}$ & $\begin{array}{l}\text { Full recovery } \\
(n=27)\end{array}$ & p Value \\
\hline Age (years) & $58(11)$ & $60(9)$ & $57(12)$ & NS \\
Sex (\% male) & 78 & 83 & 70 & NS \\
Site of infarction (\% anterior location) & 43 & 39 & 52 & NS \\
Thrombolytic treatment & $21(75 \%)$ & $14(77 \%)$ & $20(74 \%)$ & NS \\
Time to treatment (min) & $177(101)$ & $149(94)$ & $127(113)$ & 0.008 \\
$\quad \leqslant 140$ minutes & $12(41 \%)$ & $11(61 \%)$ & $20(74 \%)$ & 0.008 \\
Non-Q wave infarction & $1(3 \%)$ & $4(22 \%)$ & $10(37 \%)$ & 0.002 \\
Peak creatine kinase (IU/1) & $2251(1657)$ & $1706(929)$ & $1340(842)$ & 0.008 \\
Time to peak of CK (h) & $16.1(5.7)$ & $13.2(6.4)$ & $11.7(4.9)$ & 0.009 \\
Score index at baseline & $1.38(0.28)$ & $1.41(0.20)$ & $1.31(0.10)$ & NS \\
Contractile reserve & $4(14 \%)$ & $15(83 \%)$ & $20(74 \%)$ & $<0.0001$ \\
Residual ischaemia & $10(35 \%)$ & $14(77 \%)$ & $15(52 \%)$ & NS \\
Residual stenosis (\%) & $78(19)$ & $76(18)$ & $77(16)$ & NS \\
Minimum lumen diameter (mm) & $0.73(0.74)$ & $0.73(0.57)$ & $0.80(0.69)$ & NS \\
PTCA & $10(34 \%)$ & $12(67 \%)$ & $22(81 \%)$ & 0.0004 \\
\hline
\end{tabular}

Values are mean (SD) or $\mathrm{n}(\%)$ unless specified otherwise.

$\mathrm{CK}$, creatine kinase; PTCA, percutaneous transluminal coronary angioplasty.

Table 3 Independent predictors of functional recovery

\begin{tabular}{|c|c|c|c|c|}
\hline \multirow[b]{2}{*}{ Variable } & \multicolumn{2}{|c|}{ No recovery $v$ full recovery } & \multicolumn{2}{|c|}{ No recovery $v$ partial recovery } \\
\hline & $\chi^{2}$ & p Value & $\chi^{2}$ & $p$ Value \\
\hline Contractile reserve & 17.2 & 0.0001 & 17.0 & 0.001 \\
\hline Non-Q wave infarction & 10.1 & 0.0016 & - & NS \\
\hline PTCA & 4.53 & 0.033 & - & NS \\
\hline
\end{tabular}

PTCA, percutaneous coronary angioplasty.

partial recovery and absence of recovery. No other variable contributed independently to this distinction.

\section{Discussion}

Our study shows that in the present era of thrombolytic treatment, a substantial proportion-more than one third (36\%) - of consecutive patients presenting with ST segment elevation in the setting of a first uncomplicated acute myocardial infarction have normal myocardial thickening one year after the acute event.

To our knowledge, this is the first study to distinguish between partial and full recovery of contraction. The patients in whom regional resting function normalised were more likely to have the following: early thrombolytic treatment; a minor degree of necrosis as indicated by a small enzyme rise; an early enzyme peak; a non-Q wave infarct; and contractile reserve inducible by dobutamine infusion. Elective PTCA of the infarct related artery was more often performed in patients with improvement in regional function at one year, and was an independent predictor of full but not partial recovery.

\section{FUNCTIONAL RECOVERY}

The major determinant of functional recovery after acute myocardial infarction is the transmural extent of the infarct. The respective proportions of myocardial salvage and necrosis relate to the total time of vessel occlusion and the completeness of reperfusion. ${ }^{2}{ }^{12}$ The time course of recovery depends on the duration and severity of postischaemic myocardial ${ }^{13}$ and vascular $^{14}$ stunning and on the development and reversal of myocardial hibernation. Too early follow up may result in underestimation of the extent of functional improvement, which can continue to progress. ${ }^{9}$
IMPORTANCE OF EARLY TREATMENT

Several studies have emphasised the importance of the timing of thrombolytic treatment. ${ }^{12} 1516$ Although time of symptom onset and of initiation of thrombolysis does not correspond to vessel occlusion and reperfusion, time to treatment provides an estimate of the total time of coronary occlusion. The concept of the "golden hour" is supported by both experimental and clinical studies. ${ }^{16}$ In this study, the mean treatment delay was different in the three subgroups, with an interval of 50 minutes between patients who recovered fully (127 minutes) and those who did not recover (177 minutes). Reperfusion causes earlier enzyme release and washout. Earlier peak CK was observed in patients who recovered. In addition, compared with patients without recovery, mean peak CK was significantly lower in patients with partial recovery, and even lower in those with full recovery. Although infarct size was not calculated, these enzyme data indicate that patients who recovered fully had a smaller amount of necrosis. A small acute myocardial infarct often represents an incomplete infarction with myocardium at jeopardy. Both early peak in plasma $\mathrm{CK}^{17}{ }^{18}$ and low peak $\mathrm{CK}^{19}{ }^{20}$ have previously been found to identify a subset of patients at high late risk, who can benefit from coronary revascularisation.

INFLUENCE OF CORONARY REVASCULARISATION The need for revascularisation of the culprit lesion to achieve functional recovery of viable myocardium at jeopardy after acute myocardial infarction has been shown previously. ${ }^{2122}$ Most patent infarct related arteries have a significant residual stenosis after thrombolysis. ${ }^{5}$ In this study, functional improvement was more common in the patients who underwent revascularisation, and elective PTCA of the infarct related artery was an independent predictor of full recovery at one year. Partial recovery despite elective PTCA probably reflects an admixture of necrotic and viable tissue. Functional improvement did not occur despite PTCA in 10 patients, perhaps because of extensive necrosis at the time of the acute event. Lack of recovery can also be explained by restenosis or reocclusion of the infarct related artery. ${ }^{23}$ Many patients have spontaneous improvement in perfusion of the infarcted area, probably as a result of progressive collateral recruitment; this is usually accompanied by late but partial improvement in wall thickening. ${ }^{9}$

ROLE OF DOBUTAMINE STRESS

ECHOCARDIOGRAPHY

Low dose dobutamine stress echocardiography may identify viable but non-contractile myocardium early after acute myocardial infarction and predict reversible dysfunction. ${ }^{2124}$ The infusion of both low and high doses of dobutamine and the observation of a biphasic response-initial improvement of regional thickening followed by deterioration-have been found to predict functional recovery after PTCA in patients with chronic coronary artery disease and ventricular dysfunction. ${ }^{25}$ In our 
present study, contractile reserve was detected at low dose in $35(78 \%)$ of the 45 patients with one year recovery. A biphasic response was observed in 25 of these patients, emphasising the importance of identifying viable but jeopardised myocardium. In contrast to the observations of Afridi and colleagues, ${ }^{25}$ all 10 patients with sustained improvement in contraction during the dobutamine test recovered partially (three patients) or fully (seven patients). The significance of sustained improvement differs in the acute and the chronic setting. In the acute setting, sustained improvement corresponds to stunned myocardium than can recover progressively. Akinesis without change throughout the dobutamine test was mainly found in patients who did not recover $(73 \%)$, but five patients with unchanged wall motion showed full recovery at one year. All five patients were treated by elective PTCA. The absence of any contractile reserve despite an extensive amount of viable myocardium may result from insufficient myocardial blood flow or flow reserve. ${ }^{26} 27$

\section{STUDY LIMITATIONS}

The results of this study should be considered in the light of several limitations. Our study group included only patients with small to moderate sized infarcts. Patients who developed early complications were not included, but all patients who presented with ST segment elevation at hospital admission had significant CK release, and had dyssynergy at baseline on the first echocardiogram.

The adequacy and completeness of early reperfusion were not evaluated. Persistent patency or reocclusion of the infarct related artery influence the recovery of contractile function after acute myocardial infarction. ${ }^{28}$ Coronary angiography was not repeated at the one year follow up in our study, and therefore reocclusion or restenosis cannot definitively be excluded. However, no clinical signs of ischaemia were present in any of our patients.

Quantitative measurements of the left ventricular volumes and ejection fraction were not obtained, and semiquantitative wall motion interpretation might be a limitation. Nevertheless, serial assessment of echocardiographic regional function is widely validated and accepted as an accurate method after acute myocardial infarction and revascularisation procedures. Although the distinction between hypokinesis and normal contraction may be difficult, quantitation of myocardial thickening using two dimensional echocardiography is impractical in consecutive patients.

Finally, the time course of functional improvement was not assessed by serial echocardiographic studies.

\section{CONCLUSIONS}

Late functional improvement is determined by the integration of several variables. Full recovery of contraction is not rare one year after acute myocardial infarction. Early thrombolytic treatment is a major determinant of extensive myocardial salvage. Elective PTCA of the infarct related vessel before hospital discharge is also associated with full recovery. Dobutamine stress echocardiography is useful for predicting the extent of late functional improvement, but the absence of contractile reserve does not necessarily preclude residual viability and the potential for recovery.

1 Reimer KA, Jennings RB. The wavefront phenomenon of myocardial ischemic cell death, II: transmural progression of necrosis within the framework of ischemic bed size (myocardium at risk) and collateral flow. Lab Invest 1979;40:633-44.

2 Ito H, Tomooka T, Sakai N, et al. Time course of functional improvement in stunned myocardium in risk area in patients with reperfused anterior infarction. Circulation 1993;87:355-62.

3 Sabbah HN, Marzilli M, Stein PD. The relative role of subendocardium and subepicardium in left ventricular mechanics. Am ₹ Physiol 1981;240:H920-6.

4 Lieberman AN, Weiss JL, Jugdutt BI, et al. Twodimensional echocardiography and infarct size: relationship of regional wall motion and thickening to the extent of myocardial infarction in dog. Circulation 1981;63:739-46.

myocardial infarction in dog. Circulation 1981;63:739-46.
5 Llevadot J, Giugliano RP, McCabe CH, et al. Degree of residual stenosis in the culprit coronary artery after thrombolytic administration (thrombolysis in myocardial infarction (TIMI) trials). Am f Cardiol 2000; 85:1409-13.

6 Chen C, Chen L, Fallon JT, et al. Functional and structural alterations with 24-hour myocardial hibernation and recovery after reperfusion. A pig model of myocardial hibernation. Circulation 1996;94:507-16.

7 Bourdillon PDV, Broderick TM, William ES, et al. Early recovery of regional left ventricular function after reperfusion in acute myocardial infarction assessed by serial 641-6.

8 Pfister M, Zuber M, Wenzel R, et al. Prolonged myocardial stunning after thrombolysis: can left ventricular function be assessed definitively at hospital discharge? Eur Hear $\mathcal{F}$ 1991;12;214-17.

9 Galli M, Marcassa C, Bolli R, et al. Spontaneous delayed recovery of perfusion and contraction after the first 5 weeks after anterior infarction. Evidence for the presence of hibernating myocardium in the infarcted area. Circulation 1994;90:1386-97.

10 Hausleiter J, Notle CWT, Jost S, et al. Comparison of different quantitative coronary analysis: ARTREK, CAAS, and CMS. Cathet Cardiovasc Diagn 1993; 88:405-15.

11 Anderson JA. Regression and ordered categorical variables (with discussion). $\mathcal{F}$ R Stat Soc 1984;B46:1-30

12 Hasche ET, Fernandes C, Freedman SB, et al. Relation between ischemia time, infarct size and left ventricular function in humans. Circulation 1995;92:710-12.

13 Preuss KC, Gross GJ, Brooks HL, et al. Time course of recovery of "stunned" myocardium following variable periods of ischemia in conscious and anesthetized dogs. Am Heart f 1987;114:696-703.

14 Bolli R, Triana F, Jeroudi M. Prolonged impairment of coronary vasodilation after reversible ischemia: evidence for onary vasodilation after reversible 1schemia: evidenc

15 Newby LK, Rutsch WR, Califf RM, et al. Time from symptom onset to treatment and outcomes after thrombolytic tom onset to treatment and outcomes after
therapy. $\mathcal{F} \mathrm{Am}$ Coll Cardiol 1996;27:1646-55.

16 Boersma E, Maas ACP, Deckers JW, et al. Early thrombolytic treatment in acute myocardial infarction: reappraisal of the golden hour. Lancet 1996;348:771-5.

17 Nixdorf SM, Thompson PL, de Klerk NH, et al. Prognostic significance of an early rise to peak creatine kinase after acute myocardial infarction. Am $\mathcal{F}$ Cardiol 1988;61:1178-80.

18 Cox DA, Stone PH, Muller JE, et al. Prognostic implications of an early peak in plasma $\mathrm{MB}$ creatine kinase in patients with acute myocardial infarction. $7 \mathrm{Am}$ Coll Cardiol 1987;10:979-90.

19 Piérard LA, Dubois C, Albert A, et al. Prognostic significance of a low peak serum creatine kinase level in acute myocardial infarction. Am f Cardiol 1989;63:792-6.

20 Piérard LA, Chapelle JP, Albert A, et al. Characteristics associated with early ( $\leqslant 3$ months) versus late $(>3$ months to $\leqslant 3$ years) mortality after acute myocardial infarction. Am 7 Cardiol 1989;64:315-18.

21 Barilla F, Gheorghiade M, Alam M, et al. Low-dose dobutamine in patients with acute myocardial infarction identifies viable but not contractile myocardium and predicts the magnitude of improvement in wall motion abnormalities in response to coronary revascularization. Am Heart f 1991;122:1522-31.

22 Hopkins J, Savage M, Zalewski A, et al. Recurrent ischaemia in the zone of prior myocardial infarction: results of coronary angioplasty of the infarct-related artery. Am Heart 7 1988;115:14-19.

23 Monin JL, Garot J, Scherrer-Crosbie M, et al. Prediction of functional recovery of viable myocardium after delayed revascularization in por viable myocardium after delayed diol 1999;34:1012-19.

24 Piérard LA, De Landsheere C, Berthe C, et al. Identification of viable myocardium by echocardiography during dobutamine infusion in patients with myocardial infarction utamine infusion in patients with myocardial infarction
after thrombolytic therapy: comparison with positron emission tomography. $\mathcal{F}$ Am Coll Cardiol 1990;15:1021-31. 
25 Afridi I, Kleiman NS, Raizner AE, et al. Dobutamine echocardiography in myocardial hibernation. Optimal dose and accuracy in predicting recovery of ventricular function after coronary angioplasty. Circulation 1995;91:663-70.

26 Lee HH, Davila-Roman V, Ludbrook PA, et al. Dependency of contractile reserve on myocardial blood flow. Implications for the assessment of myocardial viability with dobutamine stress echocardiography. Circulation 1997;96: 2884-91 27 Calnon DA, Glover DK, Beller GA, et al. Effects of
dobutamine stress on myocardial blood flow, ${ }^{99 \mathrm{~m}} \mathrm{TC}$ dobutamine stress on myocardial blood flow, ${ }^{99 m}$ TC pestamibi uptake, and systolic wall thickening in the presence of coronary artery stenoses. Implications for dob utamine stress testing. Circulation 1997;96:2353-60.

28 Meijer A, Verheugt FWA, Van Eenige, et al. Left ventricular function at 3 months after successful thrombolysis. Impact of reocclusion without reinfarction on ejection fraction, regional function and remodeling. Circulation 1994;90: 1706-14.

\section{IMAGES IN CARDIOLOGY}

\section{Multiple penetrating atherosclerotic ulcers of the abdominal aorta: treatment by endovascular stent graft placement}

A 70 year old man with known systemic hypertension and hypercholesterolaemia presented for diagnostic evaluation of suspected aortic dissection. Previous routine ultrasonography raised suspicion of abdominal aortic dissection in the asymptomatic patient.

Aortography showed severe atherosclerotic alterations of the aortic wall with a focal penetrating ulcer in the infrarenal aorta (A). Intravascular ultrasound (IVUS) examination revealed multiple penetrating aortic ulcers with intramural haematoma formation distal to the origins of the renal arteries extending to the aortic bifurcation $(\mathrm{B}, \mathrm{C}, \mathrm{D})$. The largest ulcer measured $12 \times 6 \mathrm{~mm}$.

In order to prevent potential rupture, a custom made stent graft (Talent, Medtronic) $34 \mathrm{~mm}$ in diameter and $90 \mathrm{~mm}$ in length (covered) was implanted via the right femoral artery. Postimplantation angiography and IVUS showed complete coverage of the ulcerated lesions (E). The postoperative course of the patient was uneventful during a follow up period of six months.

Recently, penetrating atherosclerotic ulcer of the aorta (class IV dissection) has been identified as a potential precursor of aortic dissection. Intramural haematoma formation, pseudoaneurysm, and even transmural aortic rupture have been described as complications. Based on clinical presentation alone, patients may not be distinguished reliably from those with classic aortic dissection. So far, no generally accepted therapeutic regimen has been established. Endovascular stent graft placement may therefore provide a less invasive alternative to traditional surgery in the treatment of penetrating atherosclerotic ulcers.

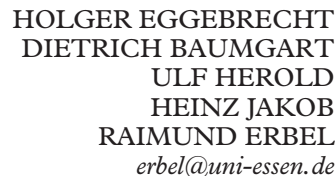

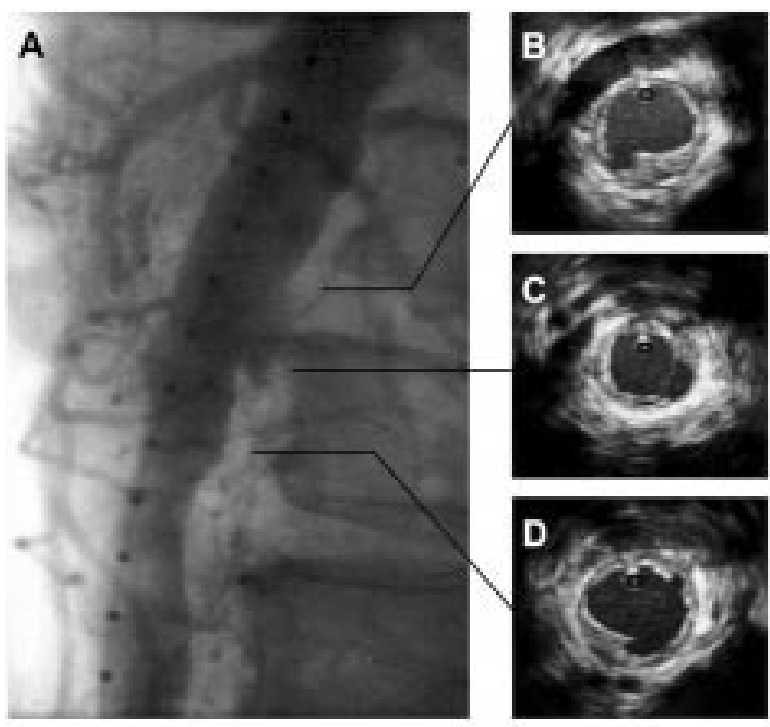

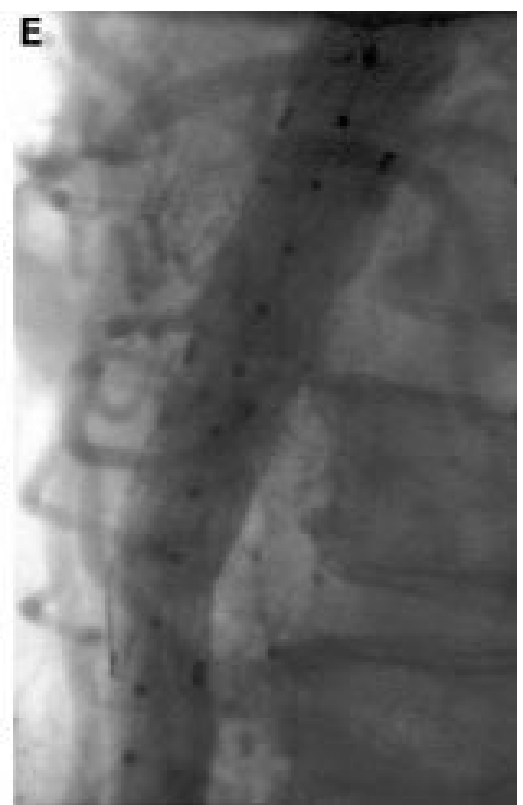

